\title{
Study on the Dilemma and Strategies for Insurance Marketing in Western Ethnic Areas
}

\author{
Jianshen Zhang ${ }^{1,} \mathrm{a}^{*}$ \\ School of Economics of Northwest University for Nationalities Lanzhou China 730030,P.R.China \\ 364221500@qq.com
}

Keywords: Ethnic regions; Insurance marketing; Insurance depth; Insurance density; Product innovation

\begin{abstract}
This paper is going to study on the insurance marketing of western ethnic areas of china, trying to find out the solutions for its dilemma and analyze the reasons with effective measures. The research methods adopted in this paper mainly include qualitative examination, quantitative examination and comparative studies. Based on the study, we will find out that the elements creating the dilemma for insurance marketing in western ethnic areas include social public, insurance companies and government policies. This paper aims to come up with some suggestions for the local insurance companies and affect the government policies. Therefore, the study will have important theoretical values as well as realistic meanings.
\end{abstract}

\section{Introduction}

Western ethnic areas refer to Ningxia, Xinjiang, Qinghai, Guangxi, Xizang, Nei Menggu, Gui Zhou, and Yunnan. Western ethnic areas have blocked transportation and do not connect with other areas for exchanges, so its economic development level lags behind. In addition, affected by the income level and ideas, local residents are not open to insurance. Based on this, to analyze the dilemma of insurance marketing in western ethnic areas with practical suggestions will have important theoretical values as well as realistic meanings. [1]

\section{Current Development Condition of Insurance Marketing in Western Ethnic Areas}

Premium Income. The economy in western ethnic areas has blossomed and the GDP has increased from 3473.483 billion Yuan in 2009 to 6477.2 billion Yuan which is almost doubled and the total income of premium also increased by a wide margin from 8,134,400 in 2009 to 14,491,900 in 2013. [2] The premium income condition of western ethnic groups from 2009 to 2013 is shown in Fig. 1.

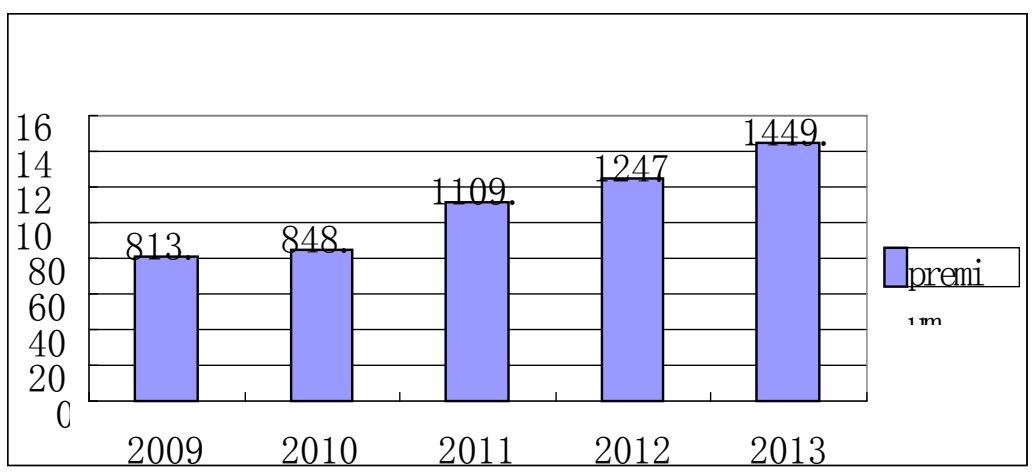

Figure 1. Premium income of western ethnic areas Unit (ten thousand Yuan)

Insurance Depth. Insurance depth refers to the ratio of premium income to gross domestic product (GDP) ratio which reflects the status of the insurance industry in the national economy as a whole. The insurance depth of the ethnic area of Western China in 2009 was $2.34 \%$ with up and downs in the following years. In 2013, it was 2.23\%. Therefore we can see that the insurance depth is not enough and the national average insurance depth is 3\%, so it is lower than the average. [3] 
Table 1 Development condition of insurance in ethnic areas of western China

\begin{tabular}{|l|l|l|l|l|l|}
\hline Year & $\begin{array}{l}\text { Type } \\
\text { (ten } \\
\text { thousand } \\
\text { (t) }\end{array}$ & $\begin{array}{l}\text { Premium } \\
\text { income (ten } \\
\text { thousand) }\end{array}$ & $\begin{array}{l}\text { GDP } \\
\text { (One } \\
\text { hundre } \\
\text { d } \\
\text { million } \\
\text { ) }\end{array}$ & $\begin{array}{l}\text { Insurance } \\
\text { Depth } \\
(\%)\end{array}$ & $\begin{array}{l}\text { Insurance } \\
\text { Intensity } \\
\text { (ten thousand) }\end{array}$ \\
\hline 2009 & 19059 & 813.44 & 34734.83 & 2.34 & 0.0427 \\
\hline 2010 & 18844 & 848.28 & 42053.2 & 2.01 & 0.0450 \\
\hline 2011 & 18946 & 1109.79 & 51844.24 & 2.14 & 0.0586 \\
\hline 2012 & 19076 & 1247.70 & 58518.5 & 2.13 & 0.0654 \\
\hline 2013 & 19214 & 1449.19 & 64772 & 2.23 & 0.0754 \\
\hline
\end{tabular}

Data source: Statistical yearbook and insurance data

Insurance Density. Insurance density refers to the average premium which reflects the development level of insurance business in the region. Insurance density in ethnic areas in West China in 2009 was 427 Yuan and 754 in 2013 with an increase. However, there is still a large gap comparing to the national average 1500 Yuan, showing in Fig. 2.

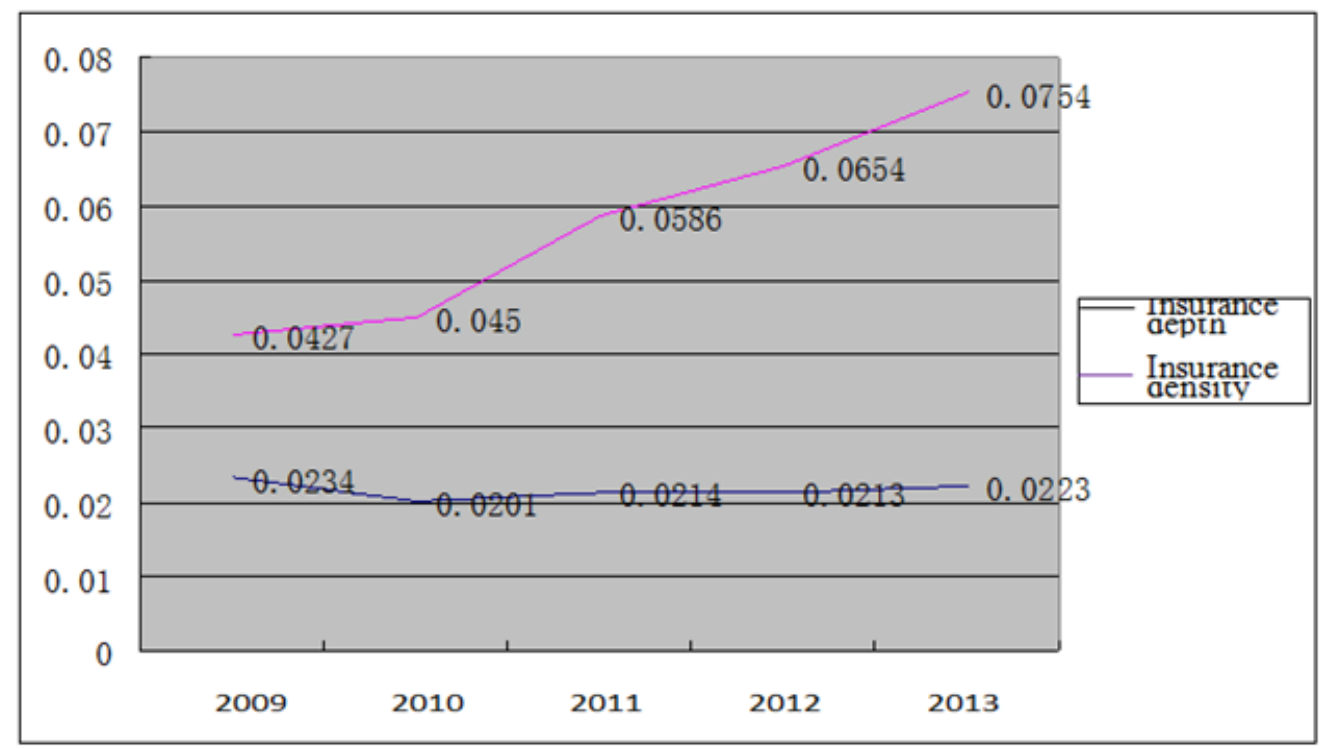

Figure 2. Insurance density and depth in ethnic areas of western China

Data source: Statistical yearbook and insurance data. [4]

\section{Dilemma and Strategies for Insurance Marketing in Western Ethnic Areas}

Social Public. Even though the disposable income for people in ethnic areas of Western China has increased a lot, most people are not willing to buy insurance products which are not must. In addition, inflation in recent years is becoming worse and worse so more people are reluctant to use spare income to invest in or purchase affordable financial products. Because of increasing pressure force, people tend to buy necessities and ignore insurance products.

The development level of science, education, cultural development in ethnic areas of western China is not high, so people do not have a knowledge of function and significance of insurance. In addition, historical reasons restricted the industry's development in ethnic area of Western China, some traditional concepts, including raise children to provide against old age, children will take care 
of parents when they become ill etc. [5]All these will lead to the lack of insurance and limit the development of insurance.

In China, especially in the underdeveloped Ares people are more willing to deposit their revenues at the Bank, trust the bank, and consider the insurance as a pyramid scheme. This awareness of asset investment has seriously hindered the development of China's insurance industry.

Insurance Companies. What's more, the insurance market is not developed enough without creativity and has convergence. Although more and more insurance products emerge, there are few which are able to meet the different needs of different level customers and the insurance portfolio is limited. In addition, there is a serious problem of convergence while the insurance terms are almost same which are not designed based on customer's real needs.

Currently, domestic insurance market adopts an extensive operation, and insurance companies often pay attention to development status of competitors and ignore market and customer. Therefore, employees in insurance companies ignore market research and forecast so there is not enough study on product design, market requirement and market segment and they don't have a clear understanding of customer needs, basic data. As a result, product development is separated from market and cannot satisfy the different needs and cannot develop the market. Some of the insurance companies try to develop business based on expanding the sales team, so they actually focus on marketing extension rather than connotation. [6] They did not take customers as the core, so it is difficult to have sustainable development.

The marketing mode of agents is the most important channel, however its disadvantages become obvious. Between insurance companies and individual insurance agents, the contract ties them together so it is agency by agreement rather than employment relationship. This kind of relationship will make agents think that they don't have backup and they will change companies frequently.

Sales people in insurance companies are not equipped with professional marketing knowledge. They only have one or two weeks of training after being recruited so they cannot understand the complicated insurance terms and they will make misunderstandings. Driven by benefits, some sales people do not have morality and they will exaggerate and significantly affect the reputation.

Relevant insurance law system in China is mainly composed by Insurance Law of the People's Republic of China, Contract Law of the People's Republic of China and General principles of the civil law of the people $\mathrm{s}$ republic of china. This system does not cover a lot with lots of loopholes. In terms of supervision, relevant offices singly emphasize promotion as well as premium income and do not pay attention to insurance companies' ability to pay and assessment management. Moreover, they don't supervise on the management. [7]

What's more, the insurance qualification examination system has not been established. The only one is agent qualification examination and the threshold is low. As a result, they are not equipped with professional qualities and there is a lack of talents. While in the developed countries such as Europe and America, it is not only about taking an agent qualification examination, they have to pass multiple exams which are really difficult.

\section{Solutions for Insurance Marketing in Western Ethnic Areas}

Social Public. Western region should seize the opportunities of the Belt and Road and Go-West Campaign to vigorously develop ethnic tourism and economy based on their own geographical, cultural and historical reasons so as to improve the income of local residents and let them have adequate capital to consider insurance products. [8]

We should make every effort to strengthen the concept of insurance. One way is to promote the idea of insurance to change people's mind and establish a sense of insurance; secondly, we should combine the reality and neighborhood committees should take the initiative to promote the insurance; thirdly, strengthen the school insurance education and introduce insurance to schools to change the concept and establish a sense of insurance.

Insurance Companies. Strengthen the intensity of market research, make insurance segment, properly locate target market. Through market research and segmentation, insurance companies can 
determine their target market and the marketing strategy. Starting from the root, people can understand that the basic function of insurance is guarantee. [9] Based on this, we can differ insurance from savings and other investments. Therefore, insurance companies should increase the intensity of market research, make market segment and properly locate the target. Insurance companies in western China should study and develop insurance products based on local characteristics to satisfy different needs of different customers.

Change marketing concept, establish insurance marketing concept of taking customers as the core. To begin with, we should innovate insurance products based on the needs of customers. The design of insurance products should satisfy customers' needs which should be changed along with the change of customers. Secondly, retain customers and change insurance service methods and philosophy. [9] Insurance companies should take advantage of their strengths to provide service with good quality so as to satisfy customers and we should cultivate loyal customers to create stable sources. [10]

The insurance company should positively explore a proper marketing channel based on their own characteristics and constantly expand insurance marketing channels. To begin with, adopt telephone to promote sales and strengthen straining. Second, strengthen cooperation between banks and insurance, insurance companies should work together with the Bank, establish long-term cooperation with powerful supervision. Thirdly, expand media marketing, we can introduce insurance information and products via television, newspapers and other mass media to establish a positive image. [11]

Insurance companies should establish a strong insurance team and rectify the marketing team, improve the quality of them. Before entering the company, insurance managers should strictly evaluate the education background and morality of employees. In addition, in follow-up training, insurance companies should pay attention to strengthen employees' professional knowledge and timely adjust the knowledge structure so as to make them be equipped with comprehensive knowledge.

Government Support. Speed up the establishment of a standardized law system to regulate the insurance. Insurance Regulatory Commission and related departments should pay more attention to insurance, insurance companies and employees as well as punishment. They should regulate the insurance actions and reduce the distrust without improper actions.

Government should step up the introduction of talent, and establish exam system of incentives and qualification inspection system, carry out comprehensive quality assessment, and cancel the unqualified agents. Government should also establish qualification exam system and realize vocational accession, upgrade the level to improve the quality of insurance employees.

\section{Conclusions}

This paper analyzes the insurance development condition in western ethnic areas from the perspectives of premium income, insurance density, insurance depth and analyzes its dilemma from the perspectives of social public, insurance companies and government. The dilemma is caused from different perspectives and we should come up with solutions based on social public, insurance companies and government. The conclusion summarized in this paper aims to give suggestions for insurance companies and affect the government in terms of policies. We believe that under the impulse of different forces and by taking advantage of the strategic opportunity of The belt and Road, we hope it can create a leap of development.

\section{References}

[1] T. He and J.L. He: Existing Problems and Innovative Paths of Insurance Marketing [J], Technological Development of Enterprise (Academic Edition), (2013) No.3,p122.

[2] Z.H. Zhang: Study on the marketing channel of insurance in China Youth Science ( Teacher Edition ) [J], (2013)No.5.p203. (In Chinese) 
[3] J.S. Wang: Study on the life insurance marketing management [J] Transactions Of Tianjin University, (2011)No.5.p103.

[4] S.P. Peng: Explore into life insurance marketing[J] Journal of Hunan Business College, (2013)No.5.p79.

[5] P. Xu: Explore into insurance marketing [J] Journal of Liaoning Administration College, (2012)No.4.p98.

[6] Y.H. Fang: Insurance Marketing [M] Shanghai: Fudan University Press, (2013).p144.

[7] B. Li: Insurance Marketing[M] Beijing: China Finance Publishing House, 2010.02. (In Chinese)

[8] H. Zhang: Study on the insurance marketing strategies based on holistic marketing[J], Shanghai Insurance, (2016)No.8.p225.

[9] L.M. Chen, J.Y. Wang and Z.Y. Liu and X.T. Zhuo, Insurance marketing in internet financial mode [J]. Finance (Academic edition), (2015)No.10.p245.

[10] N.Y. Deng: Brief talk on the innovation of insurance marketing mode in internet era [J]. Economic Research Guide , (2013)No.4.p43. (In Chinese)

[11] M. Yan: Insurance Marketing in internet financial mode [J] HUANQIU SHICHANG XINXI DANBAO, (2016)No.3.p15. 